\title{
La etnicidad y sus formas: aproximación a un modelo complejo de la pertenencia étnica
}

\section{Eduardo Terrén}

Universidade da Coruña. Departamento de Sociologia

Campus de Elviña. 15071 A Coruña

soso@udc.es

\section{Resumen}

Comprender bien la dinámica de la etnicidad y elaborar un modelo teórico de su funcionamiento que sea empíricamente contrastable es uno de los retos inexorables de la sociología de las relaciones étnicas. Tras el primer giro experimentado en este campo con el abandono del paradigma biológico de la raza, se impone ahora profundizar en un segundo giro que obligue a abandonar las visiones esencialistas de la etnicidad y a forjar visiones más complejas de los fenómenos ligados a la reproducción cultural de los grupos minoritarios. Más allá del debate entre las visiones primordialista e instrumentalista de la identidad étnica, este trabajo presenta una serie de reflexiones en torno a la necesidad de que el análisis sociológico de los fenómenos ligados a la pertenencia étnica asuma una visión de la dinámica cultural y de la formación de la identidad que permita una concepción más compleja y multidimensional del funcionamientro de la etnicidad.

Palabras clave: etnicidad, reproducción cultural, pertenencia.

\section{Abstract. Ethnicity and its forms: an approach to a complex model of ethnic belonging}

One of the main challenges of current sociology of ethnic relations is to achieve an accurate understanding of the dynamic of ethnicity and to build a theoretical model of its functioning. Decades after the neglecting of the biological paradigm of race as a scientific basis for research in this area, new theoretical work is needed towards a non-essentialist categorization of ethnicity. Beyond the perennial debate between primordialists and instrumentalists on the nature of ethnic identity, this is supposed to be the only way of forging a more complex understanding of the cultural reproduction of minority groups.

Key words: ethnicity, cultural reproduction, belonging.

Weber (1979: 315-378) reconoció que la identidad racial y el sentimiento de pertenencia basado en la afinidad grupal eran fuentes "problemáticas» de la acción social, creencias irremisiblemente ambiguas y de múltiples orígenes sociales. Incluso llegó a dudar de que la etnicidad como tal fuera un concepto adecuado para el análisis sociológico riguroso; pero, en la medida en que la 
profusión del término en la literatura sociológica actual viene a contradecir ese escepticismo, parece oportuno someter el concepto a esa labor de esclarecimiento conceptual que Merton (1995: 165-169) consideraba como una de las funciones clave de la teoría sociológica.

Uno de los principales obstáculos con que se encuentra la investigación de las relaciones interétnicas deriva precisamente de un enfoque incorrecto de la dinámica de la etnicidad. La clave de la inadecuación de este enfoque radica en proyectar sobre el objeto que pretende investigarse la rigidez semántica de la categoría bajo la que pretende subsumirse. De esta forma, la diversidad de estrategias y adaptaciones a que dan lugar las negociaciones de los individuos con las condiciones simbólicas y materiales de su entorno tiende a quedar aprisionada bajo un modelo estático y esencialista de categorización cultural. Es nuestra tesis que sólo a partir de una adecuada conceptualización del carácter abierto, diverso y complejo de la identidad y el sentimiento de pertenencia étnicos puede obtenerse una buena base para lo que Rex (1997: 270) ha señalado como el punto de partida necesario de una sociología seria de las sociedades multiculturales: «el estudio tanto teórico como empírico de la naturaleza de los grupos étnicos minotitarios y migrantes, no en la forma en que estos grupos son categorizados y clasificados por el estado, sino en la forma en que dichos grupos se ven a sí mismos» ${ }^{1}$.

Si la etnicidad es un sentimiento de pertenencia cuya investigación entra dentro del análisis de la reproducción cultural, la corrección de esta tendencia esencialista exige como primer paso una adecuada teoría de la dinámica de la cultura que nos permita ver en toda su riqueza la variabilidad de formas adaptativas que puede registrar el sentimiento de la pertenencia étnica, no sólo entre los diferentes grupos, sino incluso entre los individuos que normalmente tendemos a subsumir bajo una misma categoría étnica y cuyos comportamientos tendemos a deducir a partir de los atributos culturales que asociamos a esa categoría ${ }^{2}$.

En el fondo, como señaló Robert Park (Terrén, 2001), lo esencial de todo proceso cultural es la comunicación y, en la medida en que la etnicidad es producto de una relación cultural, las mútiples formas en que se manifiesta dependen de las condiciones en que se produzca la comunicación. El objetivo último de una adecuada conceptualización de la etnicidad radica, por tanto, a mi juicio, en

1. Teniendo en cuenta, además, cabría añadir, el hecho de que estas autopercepciones pueden estar condicionadas de diversas maneras por las heteropercepciones dominantes en una dialéctica de identidades alteroadscritas y egorreconocidas (Weinreich, 1994), como ocurre, por ejemplo, en los casos de interiorización de estigma o en los casos en que la afinidad se busca más en el exogrupo que en el endogrupo mismo.

2. Afirmar que al análisis sociológico de la etnicidad deba enmarcarse en el problema más amplio de la reproduccón cultural no significa, como veremos, que el fenómeno deba explicarse exclusivamente en términos culturales. Como señala Wieviorka (1997: 17), hablar de etnicidad no es sólo hablar de cultura, sino también —-más o menos veladamente- de raza y, por supuesto, de participación económica y política, es decir, de la división cultural del trabajo y la participación. 
liberarla de la metáfora de la frontera como línea de separación predefinida y concebirla como momento de contacto e intercambio. Esto sería algo así como «desterritorializar» la cultura, invirtiendo la tendencia que Lamo de Espinosa (1995) considera característica del romanticismo que fluye desde Toynbee hasta Huntington. Se podría decir, en definitiva, que es llevarla desde el plano del espacio al del tiempo para mostrar que, después de todo, «el grupo étnico no es en sí mismo una comunidad, sino tan sólo un momento que facilita el proceso de comunización» (Weber, 1979: 318, subrayado E.T.).

Lo que Jenkins (1997) denomina el «modelo socioantropológico de la etnicidad" proporciona una base adecuada sobre la que entender la complejidad de la dinámica cultural que caracteriza al sentimiento de pertenencia étnica. Se trata de un modelo que entronca con las reflexiones de Max Weber sobre la diferencia sentida, con la teoría de la construcción del yo social de George $\mathrm{H}$. Mead y, sobre todo, con el interés de Fredrik Barth por analizar la identidad étnica desde la perspectiva de la organización social de las diferencias culturales. Para Barth, efectivamente, el rango ontológico de las etnias en tanto que grupos no debe encapsularse rígidamente entre unos límites prefijados, pues la identidad étnica que suministra un determinado sentimiento de pertenencia es algo consustancialmente problemático, al ser constantemente producido y reproducido en las interacciones de la vida cotidiana ${ }^{3}$.

Este modelo de la «etnicidad en juego» puede sintetizarse en los siguientes supuestos: 1) que la etnicidad es una cuestión de diferenciación cultural (inexorablemente ligada, por tanto, a la dialéctica de similaridad y diferencia en que se juega la identidad social); 2) que, en la medida en que la cultura tiene que ver con la negociación de significados compartidos, la etnicidad se desarrolla fundamentalmente a través de la interacción social y contribuye a la formación de la identidad, y 3) que, consiguientemente, la etnicidad no es algo más fijo ni preestablecido que la cultura de la que forma parte.

Este modelo puede ponerse en relación con teorías de la cultura y la identidad como las de Fredric Jameson y Peter Weinreich. Jameson (1998: 101, 103), por ejemplo, señala cómo «la cultura — la versión más débil y secular de eso llamado religión - no es una sustancia o un fenómeno propiamente dicho; se trata de un espejismo objetivo que surge de una relación entre, por lo menos, dos grupos». De ello se desprende que no es estrictamente correcto decir que un grupo tenga una cultura por sí mismo, pues sólo adquiere conciencia de ella a través del contacto con lo que le es extraño. En definitiva, «la cultura debe verse siempre como un vehículo o un medio por el cual se negocia la relación entre grupos». De esa negociación surge la identidad social a la que contribuye de

3. Dentro de la ya tradicional oposición entre los enfoques primordialistas e instrumentalistas de la etnicidad, esta versión guarda una relación más estrecha con el pragmatismo de ésta última. No obstante, como ha apuntado Rex (1997: 272), tanto el aspecto emocional de la etnicidad como su utilización en el marco de una acción racional tienen su parte de verdad. A las dos versiones señaladas, Sokolovski y Tishkov (1996) añaden una tercera, la constructivista, que permite integrar ambos aspectos. 
muy diversas maneras la puesta en juego de la etnicidad, que no es, por tanto, propiedad de un grupo, sino de una relación ${ }^{4}$.

De hecho, en una línea afín a los estudios de Stuart Hall sobre la forma en que las representaciones culturales son utilizadas para marcar y sostener la particularidad y la diferencia entre grupos (Hall, 1997), la teoría de la identidad de Weinreich (1994), retomando la vieja idea de la resolución de las disonancias cognitivas, establece que los procesos de desarrollo y redefinición de la identidad se originan en una percepción siempre conflictiva, tanto de los atributos del endogrupo y del exogrupo como de las circunstancias en que se produce el contacto entre ambos. La línea de Weinreich se distancia de la de otros modelos totalizadores que, como la teoría de la elección racional de Michael Hechter o la sociobiología de Peter van den Berghe, por ejemplo, intentan reducir toda la casuística de las relaciones interétnicas a un solo modelo universal de acción. Son estos esfuerzos teóricos reduccionistas, herederos, según Yinger (1994), del sueño de una "gran teoría» que impiden el desarrollo de una aproximación multidimensional al fenómeno de la etnicidad. Por el contrario, para Weinreich (1994: 314) los procesos psicosociológicos puestos en marcha, por ejemplo, por los católicos o los protestantes de Belfast en la negociación de su identidad pueden no guardar mucha correspondencia con los desarrollados por los adolescentes caribeños o asiáticos de Bristol. El supuesto básico que subyace a su reflexión es que "las personas (al contrario que los objetos inanimados de las ciencias naturales) tienen la capacidad de crear nuevas circunstancias, generar nuevas formas de definir el mundo, inventar nuevas tecnologías e instituciones que alteran los estilos de vida y debilitan radicalmente los sistemas de valores tradicionales».

Esta línea de desarrollo teórico sintoniza claramente con la tendencia posestructuralista a mostrar la naturaleza discursiva de lo social. Por lo que a la investigación de la etnicidad respecta, esta tendencia, que bien puede entenderse como una toma de conciencia de la complejidad y el sesgo implícito de todo acto de representación, ha sido clara en un giro teórico que — con palabras de Stuart Hall- podríamos decir que va de la totalización a la articulación del objeto $^{5}$. En efecto, las discusiones más vinculadas a las teorizaciones posestructuralistas (Hall, 1992; Rattansi, 1994) han servido para poner de manifiesto el esencialismo en que había caído buena parte de la investigación de

4. Así lo muestra Thomas Hylland Eriksen (1997: 37), para quien la etnicidad sólo se crea a través de la dinámica de la relación intercultural, es decir, cuando hay un contacto y cuando los que contactan albergan una idea acerca de su diferencia cultural: «hablar de un grupo étnico totalmente aislado es tan absurdo como hablar del sonido de una sola mano aplaudiendo».

5. Este mismo giro se ha operado también en la autocrítica de la sociología feminista contra el esencialismo de la categoría «mujer». Así, por ejemplo, para Anthias y Yuval-Davis (1993) la afirmación de una "mujer genérica» oscurece la heterogeneidad de las mujeres e impide la revisión de la importancia que esa heterogeneidad tiene para la teoría feminista y la actividad política. A su juicio, la deconstrucción de la categoría «mujer» abre el camino de un análisis que puede ocuparse de las diversidades y de los puntos en común que existen entre las mujeres, partiendo de una gran variedad de contextos sociales, étnicos y de clase. 
tipo culturalista, un esecialismo que tiende a hacer ver a los miembros de las mayorías culturales como inequívocamente portadores de un racismo más o menos manifiesto y a los de las minorías como portadores no menos inequívocos de una identidad igual y específica para cada grupo, así como de una similar experiencia de racismo.

Este esencialismo es el que muchas veces impide ver que «en el mundo moderno la identidad siempre es un juego abierto, complejo y sin fin, algo siempre en construcción ${ }^{6}$. Este esencialismo epistemológico puede verse como una extensión de lo que Hall denomina el «absolutismo étnico» y su visión cerrada de la cultura y la comunidad, un absolutismo que impide reconocer muchos fenómenos asociados al carácter híbrido de la vida de quienes «portan rasgos de culturas particulares, de tradiciones, lenguajes, sistemas de creencias, textos e historias que los han modelado [...] [pero que] ya no estarán nunca unificados en el viejo sentido porque son inevitablemente el producto de varias historias y culturas entrecruzadas que pertenecen a varios "hogares" al mismo tiempo - y, por tanto, a ninguno en particular». En este mismo sentido, Paul Gilroy (1987: 61) ha hablado de una visión absolutista que condena a las culturas como expresiones fijas y mutuamente impermeables de identidad racial; una visión recurrente en el «sentido común racial» y en algunas posiciones multiculturalistas, pero que dista mucho de ser ajustada a la realidad estudiada.

De estas discusiones cabe extraer la necesidad de reconocer ese tipo de relación social que constituye la relación interétnica como algo necesariamente complejo y frecuentemente contradictorio, pues la etnicidad no es una esencia inmutable que condicione unilateralmente el comportamiento de los individuos. La etnicidad es un criterio de pertenencia basado en un conjunto de ideas, símbolos y sentimientos constantemente recreados y redefinidos en la práctica cotidiana de los individuos al vincular su identidad con la afiliación a grupos que se consideran caracterizados por alguna particularidad cultural.

La necesidad de reorientar el estudio de la etnicidad hacia una mayor sensibilidad con las diferentes formas en que se acopla sobre procesos de identificación, protagonizados por individuos con muy diversos proyectos, expectativas y experiencias de movilidad se deja ver, por ejemplo, en una reflexión sobre la categorización étnica de los jóvenes inmigrantes, como la presentada por Véronique de Rudder (1997).

De Rudder se apoya en trabajos empíricos que muestran la variabilidad de las formas de organización, de las relaciones internas y de los recursos simbólicos y materiales de las comunidades étnicas residentes en Francia. Muy sensible a los problemas de categorización de un campo de investigación «demasiado político e insuficientemente científico», de Rudder reflexiona sobre las consecuencias epistemológicas que conlleva la tendencia de los actores institucionales a construir modelos de afiliación étnica que terminan imponién- 
dose a las experiencias de los individuos categorizados. Estos modelos tienden a reificarse, "pasando por "reales" cuando no son más que construcciones formales; cuando no son, en el mejor de los casos, más que ideales abstractos nunca realizados ni "puros"” (1997: 21). Esta tendencia tiene el riesgo no ya de forzar a que lo real se conforme al modelo, sino de ocultar prácticas que pueden contradecirlo.

Esta reflexion tiene la virtud de mostrar que la reificación y la fijación de categorías étnicas proporciona al análisis de las relaciones étnicas una base conceptual ciega al carácter multidimensional de la identificación social e insensible a la presencia frecuentemente lábil y fluctuante de la etnicidad. Esta insensibilidad deriva del hecho de utilizar como criterio de inclusión una etiqueta identitaria basada en un concepto excesivamente rígido y ahistórico de los orígenes. Según De Rudder, esto conlleva implícitamente una noción de la heredabilidad que, además de ser difícilmente sostenible desde un punto de vista sociológico, es muy explotable desde el punto de vista del conservadurismo cultural tan afín al discurso de los orígenes nacionales ${ }^{7}$. Pero lo cierto es que en esto el sentido común racial basado en la estereotipia y la lógica censal o estadística coinciden. Además, la utilización de tipologías es un recurso legítimo en las ciencias sociales; y — qué duda cabe- una vez construidas, estas categorías permiten comparaciones a través del tiempo y del espacio. No obstante, aun aceptando que los grupos a que se refieren las categorías étnicas se hayan mantenido relativamente estables, cabe preguntarse si lo que permanece es la representación misma o la realidad que pretende subsumirse bajo una determinada figura social ${ }^{8}$.

7. Para un estudio de la relación entre el auge de la extrema derecha y la obsesión por los orígenes, véase Lapierre (1995), que analiza el caso francés. Este conservadurismo, por supuesto, hace referencia a quienes Alibhai-Brown (2000), en su análisis del caso británico, describe como encandilados con la visión de una cultura nacional que debe ser preservada de toda contaminación; pero también — y ella misma señala esta ironía - a quienes entre las poblaciones británicas no mayoritarias identifican esa cultura con la pérdida de sus raíces y, en vez de redefinirla, reivindican, por ejemplo, escuelas segregadas. Para Alibhai-Brown ambas posiciones se esfuerzan en sostener un viejo modelo multicultural basado en la idea de que existe «una» cultura blanca mayoritaria rodeada de extrañas culturas étnicas minoritarias y atomizadas en sus bordes.

8. Los debates actuales sobre la clasificación censal de las minorías étnicas en el Reino Unido o los Estados Unidos ejemplifican la tensión existente entre la eficacia política y el ajuste científico a la realidad, entre el cuadro sistemático de una adscripción objetiva poco ajustada a la realidad mucho más heterogénea de la etnicidad y un cuadro difícilmente sistematizable de adscripciones subjetivas o autodesignaciones que se complica a medida que se suceden las generaciones de poblaciones procedentes de la inmigración y que aumentan los casos de uniones conyugales interérnicas. Es significativo a este respecto que Newsweek (18 septiembre, 2000) concibiera su portada y sus reportajes centrales bajo el título: «Redefining race in America». Ya antes Waters (1990), con base en estudios como los realizados con Lieberson sobre la identificación étnica de individuos entrevistados en dos puntos temporales dintintos (Waters y Lieberson, 1986) da muestra de una fecunda línea de investigación acerca del gran margen de elección implícito en la autoidentificación étnica, por más que esto sea algo contrario a la intuición de la concepción popular de la etnicidad. 
Este tipo de problemas se plantean, por ejemplo, en la categorización de los descendientes de las poblaciones inmigrantes, es decir, de individuos cuyos orígenes (tanto en sentido jurídico como cultural) no son los mismos que los de sus padres ni que los de los individuos de la sociedad receptora con quienes compartirían otras variables como la edad, el sexo o la posición socioeconómica (del estudio de este caso proviene la base empírica en que se apoya la reflexión de De Rudde). Problemas similares de ajuste conceptual se plantean también cuando categorizamos como étnicas situaciones de minorización cultural en las que las diferencias que podríamos considerar étnicas pueden tener fundamentos muy diversos y dar lugar a estructuras organizativas y adaptativas igualmente diversas, desde los casos más o menos aislados de recién llegados hasta las comunidades autóctonas históricamente separadas o marginadas (Giménez, 1996; Wieviorka, 1997: 17 s.).

Ante la aporía a que da lugar este dilema entre la necesidad del recurso a las categorizaciones y la conciencia de su escasa relevancia para una correcta comprensión de la dinámica de la etnicidad, De Rudde apuesta por abrir paso a una concepción más procesual, tanto de la formación de colectividades concretas más o menos durables como de su construcción identitaria: «no queda más que una vía incierta en la que sólo la historia - y especialmente la que viene de la mano de una sociología reflexiva del conocimiento- podrá conjugar validez y fecundidad. La vía de una perspectiva resueltamente relativista y, en consecuencia, constructivista» (1997: 41).

La utilidad de esta perspectiva a la hora de destacar el carácter negociado e irremediablemente problemático de la etnicidad se pone especialmente de manifiesto cuando se analiza desde el punto de vista de la identidad y la experiencia de los sujetos implicados en una relación de contacto intercultural. Esto es lo que ocurre en buena parte de la reciente investigación etnográfica que tanto ha contribuido a resaltar el carácter complejo de la etnicidad.

Su estudio de la etnicidad desde el punto de vista de la gestación de las identidades de grupo ha supuesto un claro contrapunto a lo que desde su perspectiva se considera como un claro déficit de las campañas y las medidas oficiales contra el racismo y la xenofobia. Dicho déficit estriba fundamentalmente en que esa especie de antirracismo oficial no ha tenido apenas en cuenta las formas reales en que el racismo y los patrones ideológicos de exclusión social entran a formar parte de la práctica cotidiana y la cultura vivida de la gente. La superación de este déficit puede considerarse a buen seguro como el motivo fundamental de toda esta literatura sobre las «nuevas etnicidades».

La apuesta de esta línea de investigación se basa en primer lugar en un reconocimiento tanto de la validez como de las limitaciones de los estudios etnográficos a la hora de abordar lo que constituye su principal objeto de estudio: la etnicidad desde el punto de vista de la formación de la identidad. Puede considerarse significativa a este respecto la reflexión de James Clifford (1989), que ha contribuido a poner de manifiesto la urgente necesidad de referir todo intento de interpretación cultural a cuestiones de reconocimiento que pongan 
a un mismo nivel de relevancia las narrativas de los sujetos estudiados y las de quienes los estudian.

La invitación etnográfica de esta perspectiva, sin embargo, no alberga ninguna pretensión absolutista que lleve a hacer de la etnografía un árbitro privilegiado de lo que realmente ocurre en las calles. Contra lo que David Parker (1995) ha calificado como un "realismo estratégico» que atribuye a la etnografía una desmesurada capacidad de dilucidación de la verdad y una especie de colonización de lo antropológico, la perspectiva del estudio de las nuevas etnicidades apunta más bien hacia el reconocimiento de que la etnografía supone, más bien, un experimento con la verdad que nunca puede ser completado de forma concluyente. Clifford (1986: 7) ha resumido así este punto: «Incluso los mejores textos etnográficos — serias ficciones de verdad- son sistemas o economías de la verdad. El poder y la historia operan a través de ellos de una forma que sus autores no son plenamente capaces de controlar. Las verdades etnográficas son, pues, inherentemente parciales, comprometidas e incompletas». Su apuesta metodológica se basa, en definitiva, en una epistemología modesta.

Pero en esta epistemología modesta radica la posibilidad de no condenar el fenómeno investigado a la tiranía de las categorías, de hacer más sensible la teorización a la experiencia real de los sujetos investigados. El reto es, en este sentido, evitar la comodidad de los discursos establecidos basados en lo que Foucault llamó «tiranía de los universales» y Barthes, la «simplicidad de las esencias». Es decir: de lo que se trata es de evitar viejas dependencias epistemológicas que llevan a plantear las cuestiones multiculturales en función de simples arquetipos culturales cuya esencia metafísica no hace sino reificar conceptos como los de «minoría» o «etnia» y, en última instancia, presentar las culturas estudiadas como unidades absolutas herméticamente cerradas.

Para ello no basta con reconocer la relación que ha guardado el racismo con la construcción de las identidades colectivas en la historia del romance de la ciencia social europea con los no europeos (Jenkins, 1997; Terrén, 2002). Debe irse más allá y sumergirse en las profundas transformaciones que está sufriendo hoy día la semántica social de la raza, la nacionalidad y la identidad. La clave de un adecuado estudio de la diversidad cultural no radica sólo en hacer la crítica de las lógicas pseudocientíficas que antaño servían de base a la jerarquización de la diversidad, algo que ya se hizo en la teoría social de la posguerra. Radica, más bien, en superar ese «absolutismo étnico» que esclereotiza la verdadera naturaleza cambiante de la vida social y cultural de los individuos que subsumimos bajo categorías étnicas.

Así lo sugiere una investigación que podemos considerar como paradigmática para nuestro caso. El trabajo de Back (1996) ${ }^{9}$ aborda el dinamismo

9. Dentro de la tradición etnográfica anglosajona, esta investigación cuenta con un claro precedente, el trabajo de Paul Willis sobre los jóvenes estudiantes de clase obrera, que aborda también el problema de los estilos de vida juveniles desde una óptica etnográfica en la que los significados culturales aparecen en un proceso de negociación constante. 
inherente a la vida cultural de las nuevas etnicidades al estudiar a la juventud que habita en zonas multirraciales del sur de Londres. Back se centra en investigar las prácticas culturales a través de las cuales diversos grupos de adolescentes de dos barrios londinenses confieren al estereotipo de la raza significados específicos en contextos diferentes. Lo que subraya el estudio comparativo de estos contextos multiculturales son los procesos de intercambio e hibridación cultural en que se gesta la dinámica de la etnicidad. Back compara la reproducción de esta dinámica en un contexto de clase obrera blanca y otro étnicamente mixto. Interesa aquí especialmente destacar algunos de los conceptos clave que se instrumentalizan en la investigación.

Desde el punto de vista de los procesos de estructuración social en que se enmarcan los discursos de formación de la identidad es interesante reparar, por ejemplo, en el concepto de «discurso comunitario», concepto que se prefiere al de «ideología» porque sugiere una naturaleza menos estable y una presentación menos formalizada en cuanto a su consistencia semántica. Puede verse en ello seguramente un distanciamiento de los modelos tradicionales de análisis de las conciencias de clase, rígidamente vinculadas las más de las veces a algún tipo de determinación estructural. Frente a ello, el tipo de construcción cultural a que se refiere el discurso comunitario permite mostrar la dinámica esencial de lo que podríamos denominar la «etnicidad vivida»: la propia visión de la comunidad se presenta, así, como una construcción discursiva utilizada como recurso cultural en toda situación cognitiva que hace uso de definiciones inclusivas o exclusivas (dentro / fuera, nosotros / ellos). En la reconstrucción etnográfica de las diferentes «voces» que intervienen en la formación del discurso comunitario, Back presta una especial atención a los diversos estilos de vida locales, con lo que retoma uno de los aspectos básicos del estudio sociológico del estatus, no siempre identificable con los intereses (de clase) que cabría deducir de la posición de los sujetos estudiados en el sistema económico.

El sistema de significados constantemente negociado en los procesos simbólicos de construcción de la identidad colectiva se concreta, para Back, en una forma específica de discurso comunitario denominado «nacionalismo de vecindario" (neighbourhood nationalism). Las diversas formas de este nacionalismo reproducen, de forma no mecánica y siempre mediada por las condiciones históricas locales, los elementos de inclusividad y exclusividad que caracterizan a ese etnocentrismo que parece albergar toda forma de nacionalismo. Sin entrar ahora en la oportunidad del concepto, baste señalar su utilización como muestra de la forma en que se analiza la influencia del contexto social comunitario sobre la construcción de la identidad, huyendo de esencialismos y subrayando el carácter inequívocamente multifactorial y negociado de dicha construcción. Ciertamente, como afirma Hall, las identidades «no están acorazadas una frente a otra» ni se forjan de igual forma en diferentes contextos.

Así, por ejemplo, aunque la importancia de los argumentos raciales en la explicación del declive de las condiciones de vida de uno de los barrios estudiados por Back es un componente importante en el discurso comunitario elabora- 
do por la población adulta, cabe apreciar que los jóvenes, más expuestos a ciertas formas de sincretismo cultural, no reproducen pasivamente este patrón adscriptivo. La construcción cultural de la identidad de estos jóvenes tiende a rechazar el color de la piel en sus estrategias de interpretación de la comunidad, dando lugar a una especie de sincretismo cultural de los jóvenes negros y blancos de clase obrera. Sin embargo, la investigación de Back muestra cómo su común identificación como miembros de la comunidad local no está exenta de ciertos motivos racistas frente a negros de otras zonas o frente a miembros de otras comunidades étnicas como, por ejemplo, los vietnamitas, claramente estigmatizados como outsiders. Se ve, así, cómo los mismos puentes de comunicación y sincretismo cultural que sirven para negociar algunas formas de fusión cultural pueden servir para marcar ulteriores diferencias que generan nuevas estigmatizaciones y exclusiones. Por otro lado, así como estos jóvenes blancos y negros de uno de los barrios comparten un mismo nacionalismo de vecindario, los jóvenes negros de otro reconstruyen su identidad sin referencia alguna a un contexto compartido con los blancos. En este caso, el discurso comunitario de la etnicidad se construye sobre una idea de la negritud como norma de solidaridad e identificación supralocal que lleva a ver como «hermanos» o "compañeros de viaje» a individuos muy lejanos en el espacio y en el tiempo.

En definitiva, "quiénes somos nosotros», "quiénes somos los de aquí» o "quiénes son los nuestros», cuestiones todas ellas de identidad que subyacen a la lógica de la etnicidad, constituyen preguntas a las que individuos que superficialmente caracterizaríamos como miembros de una misma etnia pueden responder de muy diferente forma, según sean las posiciones de poder percibidas en los contextos de su práctica cotidiana y según sean los grupos de referencia respecto a los que vinculan sus patrones de afiliación.

En otros términos, y utilizando la noción weberiana del cierre social, las estrategias culturales que simbolizan dicho cierre pueden ser tan diversas como los privilegios de estatus percibidos y los estilos de vida asociados a ellos. Más allá del hecho de que muchos jóvenes estén creyendo construir una cultura y un espacio vital ajeno a adscripciones raciales, lo que una investigación como la de Back muestra es que en el interior de esa creencia fluyen complejos y profundos mecanismos que pueden llevar a lo que cabría denominar como un «racismo sin raza» o un «racismo popular». Un racismo que no se expresa de forma monolítica, sino que más bien adquiere muy diferentes sentidos (incluso a veces contradictorios) como recurso estratégico discursivo al servicio de una determinada identidad social.

Dejando ahora a un lado el problema de cómo ciertas formas de racismo popular pueden reaparecer en este constante rehacerse de la etnicidad, lo que se pretende destacar aquí es la exigencia epistemológica que parece desprenderse de esta línea de investigación y lo que aporta a la comprensión de la dinámica cultural en la que se despliega la etnicidad. La clave de esta aportación radica en recurrir a un modelo dinámico de análisis que Back encuentra adecuadamente representado en la imagen del rizoma de Deleuze y Guattari 
$(1980)^{10}$. Debe tenerse en cuenta, a este respecto, que la rizomática no proporciona tanto una nueva metáfora para el fenómeno cuanto un nuevo estilo de pensamiento que (frente al "pensamiento de Estado", unificador y dicotómico) prima en su enfoque de la realidad la multiplicidad y la heterogeneidad (Best y Kellner, 1991: 99-109). En la dinámica a la que se abre este enfoque la etnicidad no actúa como un elemento apriorístico; no interviene como una esencia determinadora, sino, más bien, como un recurso movilizado en la red de conexiones simbólicas a través de la que se forjan las estrategias de adaptación y de interpretación de la realidad. Con ayuda de esta imagen puede comprenderse la etnicidad como una práctica «liminar», es decir, constantemente redefinida y cuestionada en sus límites que sumerge las identidades y sus redes de significados en un estado de perpetuo inacabamiento. Los muros de la cultura son porosos, y por tanto también lo son los de la etnicidad ${ }^{11}$.

Sin duda, la visión de la etnicidad que se deriva de este modelo de teorización es escurridiza y polisémica, pero difícilmente podría ser de otra forma si el modelo debe poder aplicarse a todo el abanico de situaciones en las que entra en juego la etnicidad. Piénsese, por ejemplo - y la lista es meramente indicativa-, en los gitanos españoles y en los albaneses; en los afroamericanos, en los negros de Sudáfrica y en los afrocaribeños del Reino Unido; en los judíos neoyorquinos y en los del gueto de Varsovia; en los musulmanes de Yugoeslavia y en los de Francia; en los tecnoemigrantes asiáticos que ocupan los puestos más cualificados de Sillicon Valley y en los asiáticos —o más bien asiáticas - que ensamblan componentes electrónicos en talleres de penosas condiciones..., y piénsese, sobre todo, en las muy diversas estrategias de afiliación étnica que pueden desplegar los individuos y las familias en cada uno de esos casos. Todos ellos son abstracciones de trayectorias múltiples y heterogéneas de la etnicidad. Todos ellos difieren entre sí y varían considerablemente en sí mismos porque todos ellos albergan, en una proporción diferente y variable en el tiempo, elementos que favorecen la reproducción y elementos que favorecen el cambio.

Quizá, después de todo, la etnicidad aún siga siendo más un símbolo útil que un concepto bien definido — como ya en su momento advirtió Weber. Pero, desarrollado en la línea aquí apuntada, puede contribuir a ese gran reto

10. La rizomática define un campo caracterizado por la heterogeneidad y la multiplicidad que se resiste a la reducción a la unidad que pretende toda explicación. Un análisis basado en este tipo de estrategia queda reducido a una cartografía de las diversas determinaciones que atraviesan el objeto estudiado huyendo de su reducción totalitaria a una especie de calco totalitario de la realidad. Deleuza y Guattari (1980: 9-37).

11. Podría decirse que la reproducción perfecta de la identidad grupal es un absurdo sociológico, pues, como señala Wieviorka (1997: 19), «la diferencia cultural [...] es cambio, no mera perpetuación». Ni siquiera en los casos de los grupos más instalados en una definición aparentemente inmutable de su identidad ésta puede reproducirse con estricta fidelidad al arquetipo. El simple hecho de querer afirmarla ante los dominadores presupone una percepción de amenaza y un deseo de movilización que la hacen existir de una forma distinta a como supuestamente existió para los antepasados. 
teórico que consiste en subsumir bajo un mismo concepto un fenómeno interactivo tan variable como las múltiples situaciones en que se presenta. Puede, cuando menos, contribuir notablemente al desarrollo de una investigación empírica de las relaciones étnicas alejada de las fórmulas esclerotizantes del determinismo cultural y propiciar con ello una aproximación más realista al fenómeno de la etnicidad. La clave de esta aproximación radica en que la conceptualización de la pertenencia étnica no se construya (o no se construya sólo) sobre un modelo predefinido de cierre cultural y repliegue comunitario, sino que sea una conceptualización capaz de reproducir la diversidad en vez de segmentarla y que, al hacerlo, sea sensible también a las estrategias individuales de integración, a los sincretismos, hibridaciones y voluntades de asimilación. En definitiva, un modelo complejo de la pertenencia étnica es un modelo que basa su potencial teórico en interesarse más por destacar la diversidad con que la etnicidad es puesta en juego que por reducirla a la unidad de sus supuestos atributos esenciales.

\section{Bibliografía}

Alibhai-Brown, Y. (2000). After multicultualism. Londres: Foreign Policy Center. ANTHIAS, F.; YUVAL-DAVIS, N. (1993). Racialized boundaries. Londres: Routledge. BACK, L. (1996). New ethnicities and urban culture: racisms and multiculture in young lives. Londres: Univ. College.

Best, S.; Kellner, D. (1991). Postmodern theory. Critical interrogations. Londres: MacMillan.

CLIFFORD, J. (1989). Culture and truth: the remaking of social analysis. Londres: Routledge.

ClifFord, J.; MerCus, G.E. (eds.) (1986). Writing culture: the poetics and politics of ethnography. Berkeley: University of California Press.

DeleuZe, G.; GuATTARI, F. (1980). Capitalisme et schizophrenie: Mille plateaux. París: Editions de Minuit.

ERIKSEN, T.H. (1997). «Ethnicity, race and nation». En Guiberanu, M.; ReX, J. (eds.). The ethnicity reader. Cambridge: Polity Press.

GILROY, P. (1987). There ain't no black in the Union Jack: the cultural politics of the race and nation. Londres: Hutchinson.

GIMÉNEZ, C. (1996). «La formación de nuevas minorías étnicas a partir de la inmigración». En MARTín ROjO, L. et al. (coords.). Hablar y dejar hablar. (Sobre racismo y xenofobia). Cantoblanco, Madrid: Ediciones de la UAM.

Hall, S. (1992). "New ethnicities». En Donald, J.; RatTansi, A. (eds.). "Race», Culture and difference. Londres: Sage.

- (1997). «The work of representation». En HALL, S. (ed.). Representation. Cultural representations and signifying practices. Londres: Sage.

JamesOn, F. (1998). «Sobre los estudios culturales». En JAMESON, J.; ZizeK, S. Estudios culturales. Reflexiones sobre el multiculturalismo. Barcelona: Paidós.

JENKINS, R. (1997). Rethinking ethnicity. Londres: Sage.

LAMO DE EsPINOSA, E. (1995). «Fronteras culturales». En LAMO DE EsPinOSA, E. (ed.). Culturas, estados, ciudadanos. Madrid: Alianza.

LAPIERRE, N. (1995). Changer de nom. París: Stock. 
LiEBERSON, S.; WaTERS, M.C. (1986). «Ethnic groups in flux: the changing ethnic responses of American whites». Annals of the American Academy of Political and Social Science, 487, septiembre: 79-91.

Merton, R.K. (1995). Teoría y estructura sociales. México: Fondo de Cultura Económica.

PARKER, D. (1995). Through different eyes: the cultural identities of young chinese people in Britain. Aldershot: Avebury.

RatTANSI, A. (1994). “"Western racisms", ethnicities and identities in a "postmodern" frame». En RaTTANSI, A.; WeSTWOOD, S. (eds.). Racism, modernity and identity on the Westrn front. Cambridge: Polity Press.

REX, J. (1997). "The nature of ethnicity in the project of migration». En Guibernau, M.; Rex, J. (eds.). The ethnicity reader. Cambridge: Polity Press.

RUDDER, V. de (1997). "Quelques problèmes épistémologiques liés aux définitions des populations immigrantes et de leur descendance». En AUBERT, F. et al. Jeunes issus de l'immigration. París: L'Harmattan.

SoKOlovsKiI, S.; TishKov, V. (1996). «Ethnicity». En Encyclopedia of social and cultural anthropology. Londres: Routledge.

TERRÉN, E. (2001). «La asimilación cultural como destino: el análisis de las relaciones étnicas en R.E. Park». Sociológica, 4.

- ((ed.) (2002). Razas en conflicto. Perspectivas sociológicas. Barcelona: Anthropos.

WATERS, M.C. (1990). Ethnic options: choosing identities in America. Berkeley: University of California Press.

WATERS, M.C.; LieBERSON, S. (1986). «Ethnic groups in flux: the changing ethnic responses of American whites». Annals of the American Academy of Political and Social Science, 487.

Weber, M. (1979). Economía y sociedad. México: Fondo de Cultura Económica.

WeINREICH, P. (1994). "The operationalisation of identity theory in racial and ethnic relations». En ReX, J.; MASON, D. (eds.). Theories of race and ethnic relations. Cambridge: Cambridge University Press.

WieviorKa, M. (1997). «Culture, societé et démocratie». En WieviorKA, M. (dir.). Une société fragmenté? Le multiculturalisme en débat. París: La Découverte.

YINGER, J.M. (1994). "Intersecting strands in the theorisation of race and ethnic relations». En REX, J.; MASON, D. (eds.). Theories of race and ethnic relations. Cambridge: Cambridge University Press. 